\title{
ENSINO DE MODA PARA ATUAÇÃO EM NOVOS CONTEXTOS DE DESIGN E DE PRODUÇÃO: SUSTENTABILIDADE, OPEN DESIGNE FABRICAÇÃO DIGITAL
}

\author{
Fashion education for new design and production contexts: sustainability, open \\ design and digital manufacturing
}

\author{
Aguinaldo dos Santos ${ }^{1}$ \\ Iana Uliana Perez ${ }^{2}$
}

\section{RESUMO}

Este artigo tem como intuito relatar a experiência de um projeto de aprendizagem envolvendo a aplicação de conceitos do open design e o uso de tecnologias de fabricação digital para o desenvolvimento de vestuário mais sustentável. Objetiva-se discutir como preparar o designer de moda a atuar com open design e com novas tecnologias produtivas sob a perspectiva do design para a sustentabilidade. Para tanto, o método utilizado é a Design Science Research, que permitiu delinear recomendações para a capacitação de estudantes de moda para atuarem em novos contextos de design e de produção.

Palavras-chaves: Economias distribuídas. Projeto de aprendizagem. Vestuário.

\begin{abstract}
This article aims to report the experience of a learning project involving the application of open design concepts and the use of digital manufacturing technologies for the development of more sustainable clothing. The objective is to discuss how to prepare the fashion designer to work with open design and with new productive technologies from the perspective of design for sustainability. Therefore, the method used is Design Science Research, which has allowed us to outline recommendations for the training of fashion students to act in new design and production contexts.
\end{abstract}

Keywords: Distributed economies. Learning Project. Clothing.

\footnotetext{
1 Mestranda em Design pela UFPR. Bolsista Capes e pesquisadora no Núcleo de Design \& Sustentabilidade da UFPR. Especialista em Gestão Estratégica de Design (UEL) e em Moda: Produto e Comunicação (UEL). Graduada em Design de Moda (UEL).

E-mail: iana.uli@gmail.com | Lattes: http://lattes.cnpq.br/7834194247765889

2 Coordenador do Núcleo de Design \& Sustentabilidade da UFPR. Pós Doutor em Design Sustentável pelo Politecnico di Milano. Doutor em Gerenciamento da Produção (Salford University), mestre em Engenharia (UFRGS) e graduado em Engenharia Civil (UFPR).

E-mail: asantos@ufpr.br | Lattes: http://lattes.cnpq.br/7032553306249218 


\section{INTRODUÇÃO}

O ensino de moda em cursos superiores é relativamente recente no Brasil, assim como sua associação ao design. Enquanto o primeiro curso superior de design foi criado em 1963, apenas 25 anos depois, em 1988, foi fundado o primeiro curso superior de moda, o Bacharelado em Design de Moda da Faculdade Santa Marcelina, em São Paulo (CARDOSO, 2008; PIRES, 2002, 2007). Contudo, inicialmente a moda não era considerada uma especialidade do design (PIRES, 2007). Isso mudou quando o Ministério da Educação (MEC) determinou, em 2004, que os cursos com foco em moda se adequassem às Diretrizes Curriculares do Design (Ibidem; BORGES, 2017).

Pires (2007) reforça que a aproximação entre design e moda proporcionada pela resolução do MEC era inédita, tanto pelas diferentes abordagens de ensino até então adotadas, quanto pela tensão existente entre as áreas. $O$ ensino de design no Brasil teve como influência, majoritariamente, os padrões de rigor da ciência e do método da Escola Superior de Design de UIm (CARDOSO, 2008; PIRES, 2007). Por outro lado, os cursos de moda foram, em quase sua totalidade, alojados nos departamentos de artes das universidades (PIRES, 2002, 2007). Talvez essa diferença explique a "histórica resistência e tensão" entre moda e design relatada por Pires (2007). Segundo a autora, alunos "que manifestassem interesse em desenvolver produtos de moda eram quase sempre desestimulados pelos professores dos cursos de desenho industrial" (Ibidem, p. 67). A partir de 2004, essa realidade passou a mudar, pois deu-se oportunidade para iniciativas conjugadas, em que moda e design passaram a conviver em posição complementar (Ibidem).

Na Universidade Federal do Paraná (UFPR), no entanto, essa aproximação começou apenas recentemente. O curso de graduação em design da UFPR foi criado em 1975, sendo inicialmente intitulado Desenho Industrial. Atualmente, o curso apresenta duas habilitações: Design Gráfico e Design de Produto. Dentre as diversas disciplinas obrigatórias e eletivas ofertadas semestralmente para ambas as habilitações, nenhuma contemplava a moda, conquanto diversos alunos solicitassem que o tema fosse abordado no curso.

No segundo semestre de 2016, contudo, foi ofertada a primeira disciplina de moda do Departamento de Design da UFPR. Intitulada "Design de Moda para a Sustentabilidade", a disciplina foi proposta pelos autores do presente artigo sob a égide da disciplina eletiva "Tópicos Especiais em Design de Produto, que 
semestralmente dá abertura para a proposta de novos tópicos por parte do corpo docente.

Afora o desafio de ser a primeira disciplina de moda do referido programa de graduação, durante a matéria foi desenvolvido um projeto de aprendizagem envolvendo a aplicação de conceitos do open design e o uso de tecnologias de fabricação digital para o desenvolvimento de vestuário mais sustentável, iniciativa provavelmente inédita no ensino de moda e design no Brasil.

O propósito do presente artigo é relatar a experiência desta disciplina de moda, ministrada para alunos de design de produto. Mais especificamente, é relatado o desenvolvimento do projeto de aprendizagem conduzido, o qual envolveu, como mencionado anteriormente, a aplicação de conceitos do open design e o uso de tecnologias de fabricação digital para a criação e produção de vestuário mais sustentável. A partir dessa experiência, e com alicerce de revisão bibliográfica, objetiva-se discutir como preparar o designer de moda a atuar com open design e com novas tecnologias produtivas sob a perspectiva do design para a sustentabilidade. $O$ método utilizado para a investigação é descrito a seguir. Na sequência, são apresentados os resultados da revisão bibliográfica e do desenvolvimento do projeto de aprendizagem. Ao final, os resultados são discutidos e, para encerrar, algumas considerações finais são colocadas.

\section{DESENVOLVIMENTO}

A pesquisa realizada é qualitativa de caráter exploratório e de natureza aplicada. O método adotado é a Design Science Research (DSR). Segundo Dresch, Lacerda e Antunes Júnior (2015, p. 95), este "é o método de pesquisa mais indicado quando o objetivo do estudo é projetar e desenvolver artefatos, bem como soluções prescritivas, seja em um ambiente real ou não". Neste caso, o intuito é delinear recomendações para a capacitação de estudantes de moda para atuarem em novos contextos, mais sustentáveis, de design e de produção. Portanto, o resultado obtido são design propositions ${ }^{3}$, ou seja, "um template genérico que pode ser utilizado para o desenvolvimento de soluções para uma determinada classe de problemas" (VAN AKEN, 2011 apud DRESCH; LACERDA; ANTUNES JÚNIOR, 2015, p. 113).

\footnotetext{
${ }^{3}$ Proposições de design. 
Para a aplicação da DSR, utilizou-se como base o método proposto por Dresch, Lacerda e Antunes Júnior (2015), que foi adaptado para o contexto da presente pesquisa. A estratégia adotada envolveu três fases principais, como ilustra a Figura 1: compreensão do problema, desenvolvimento do artefato e avaliação.

Figura 1 - Método de pesquisa

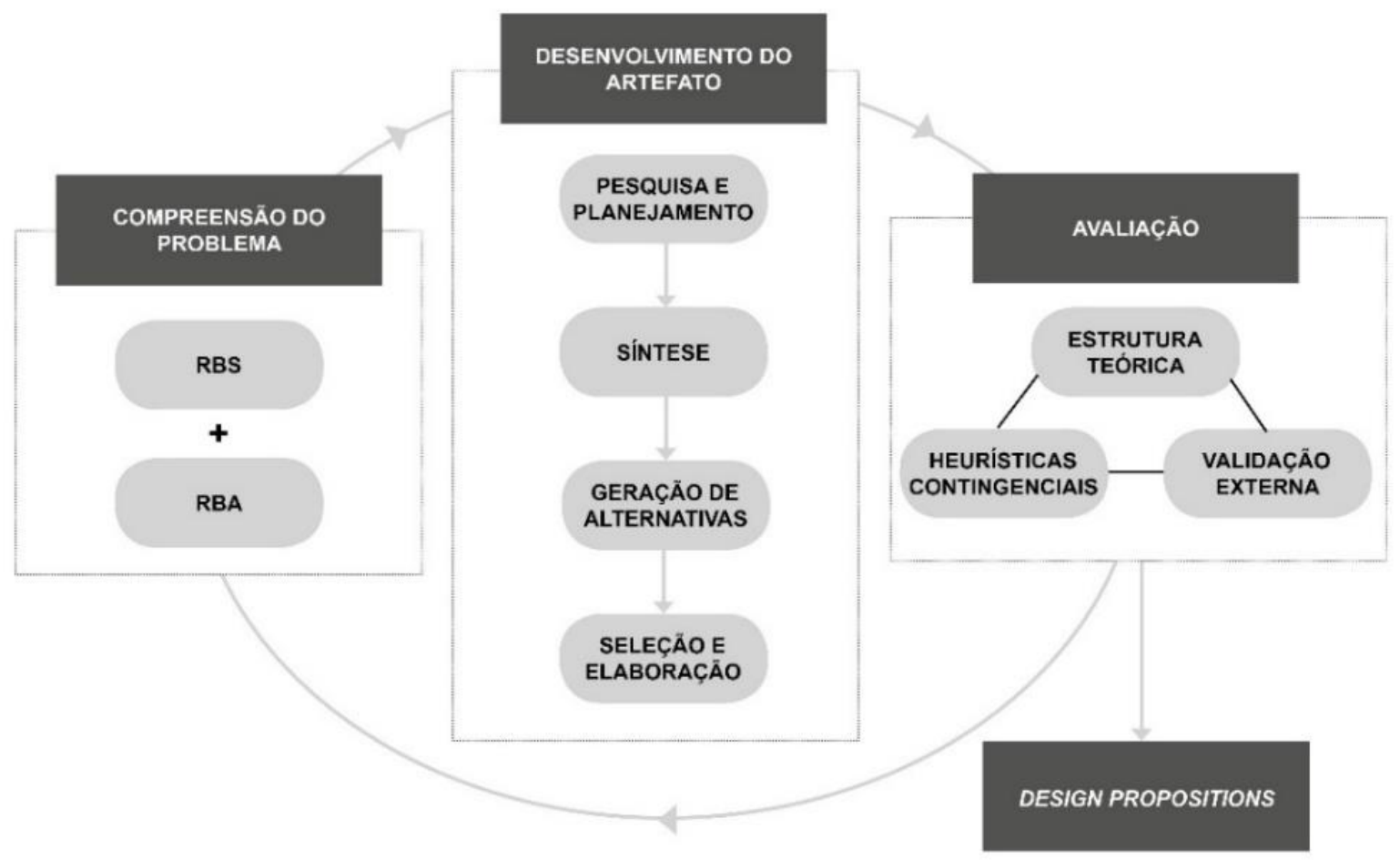

Fonte: Os autores (2017)

A prescrição é alicerçada na compreensão do problema, realizada por meio de Revisão Bibliográfica Assistemática (RBA) e Revisão Bibliográfica Sistemática (RBS) ${ }^{4}$, sendo esta última conduzida com base no protocolo proposto por Conforto, Amaral e Silva (2011). Primeiramente, foi realizada busca por trabalhos sobre design, fabricação digital e/ou open design publicados entre 2010 e 2017 na Biblioteca Digital Brasileira de Teses e Dissertações ${ }^{5}$, com a finalidade de analisar a densidade e a evolução das pesquisas sobre esses temas. Também foram realizadas buscas no Portal de Periódicos das Capes, nos anais do Colóquio de Moda ${ }^{6}$ e nos principais periódicos nacionais de moda: ModaPalavra E-periódico, dObra[s] e IARA- Revista de

\footnotetext{
${ }^{4}$ RBS é um tipo de pesquisa bibliográfica que segue um método explícito, planejado e justificável (DRESCH; LACERDA; ANTUNES JÚNIOR, 2015). Diferencia-se da revisão bibliográfica assistemática por apresentar maior rigor científico, "podendo alcançar melhores resultados e reduzir erros e o viés do pesquisador responsável pela investigação" (CONFORTO; AMARAL; SILVA, 2011, p. 2).

${ }^{5}$ Disponível em: <http://bdtd.ibict.br/vufind/>.

${ }^{6}$ Maior congresso nacional da área
} 


\section{RE ARTE \\ MODA \\ DESIGN}

Moda, Cultura e Arte 7 . Ademais, foram consultados livros, relatórios técnicos, teses e dissertações internacionais, artigos publicados em periódicos e em anais de congresso internacionais, assim como artigos publicados em sites e blogs especializados.

Os dados obtidos na revisão bibliográfica permitiram planejar o processo e analisar os resultados do desenvolvimento do artefato - no caso desta pesquisa, produtos de vestuário open design que utilizassem predominantemente tecnologias de fabricação digital. Os trabalhos desenvolvidos foram ficticiamente destinados para o empreendimento de moda holandês The Post-Couture Collective, um caso real de negócio de moda que alia open design e fabricação digital por meio da comercialização de moldes digitais e de kits de construção, os quais utilizam o corte a laser como tecnologia produtiva e permitem a construção da roupa sem a necessidade de costura à máquina (THE POST-COUTURE COLLECTIVE, 2017). O processo de design de moda adotado nesta fase teve como base Montemezzo (2003), Sanches (2008) e Gwilt $(2011,2014)$. A figura 2 resume as etapas do processo e suas respectivas atividades, sendo destacadas em magenta as alterações com relação ao processo convencional de design de moda.

${ }^{7}$ Todas as buscas foram atualizadas em julho de 2017. 
Figura 2 - Processo de design adotado

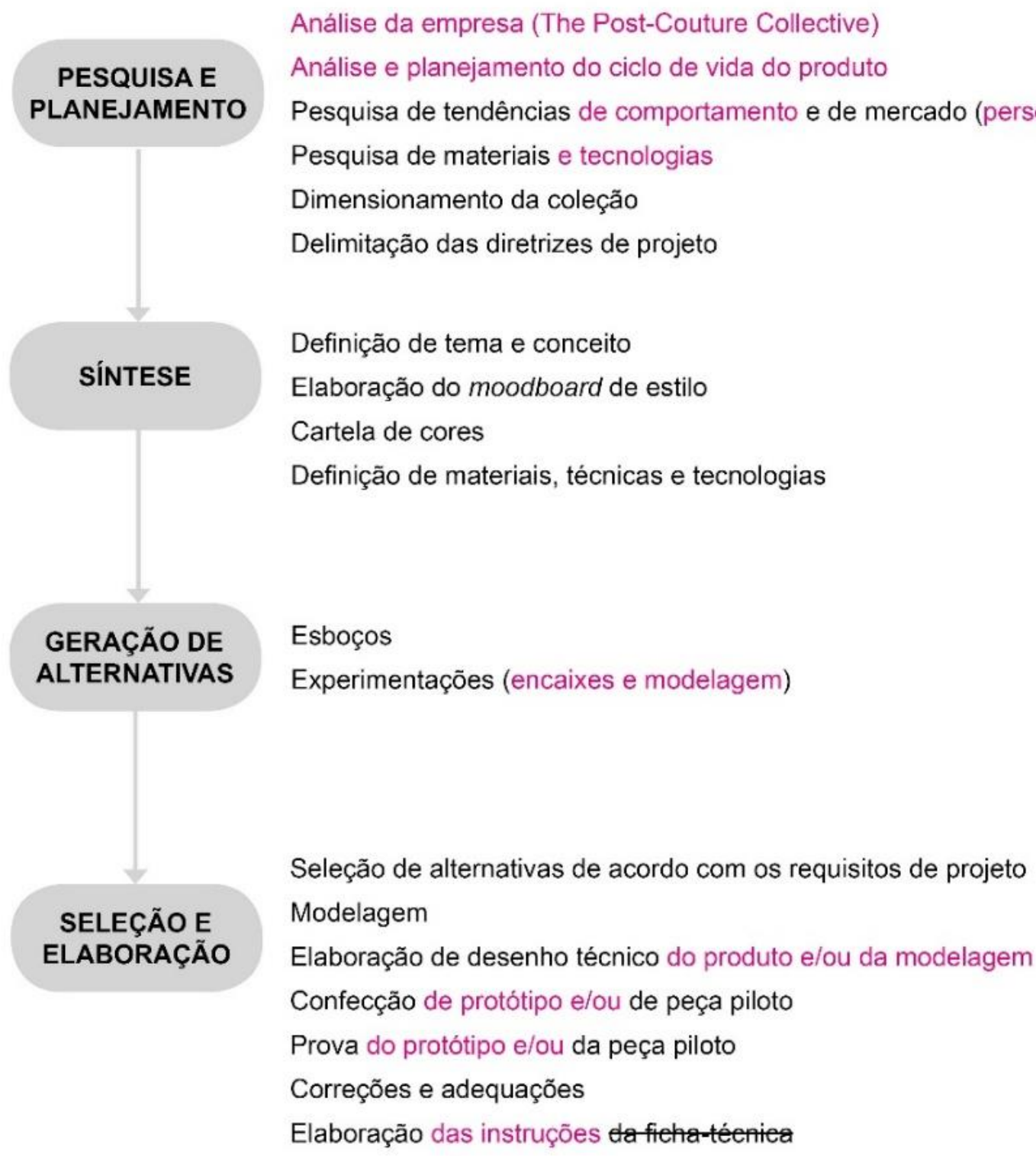

Fonte: Autora (2017)

A avaliação do processo e dos produtos desenvolvidos foi realizada com base na estrutura teórica elaborada a partir da RBA e da RBS, na validação externa com especialistas do setor de vestuário, tanto do meio empresarial quanto acadêmico ${ }^{8}$, e na formalização de heurísticas contingenciais, que, segundo Dresch, Lacerda e Antunes Júnior (2015, p. 132), permitem ao pesquisador "explicitar os limites do artefato e suas condições de utilização".

\footnotetext{
${ }^{8}$ Foram consultados três especialistas: o fundador de The Post-Couture Collective; uma empresária e diretora criativa da área de moda; uma docente de moda Ph.D especializada em design para a sustentabilidade.
} 


\section{RESULTADOS}

\subsection{Open design e fabricação digital: moda, sustentabilidade e ensino}

O open design e a fabricação digital enquadram-se no modelo de economias distribuídas (representado na Figura 3) por envolverem, respectivamente, design distribuído e produção distribuída, como aponta o projeto LeNSin ${ }^{9}$ (2016). As economias distribuídas, Segundo Vezzoli (2012, p. 41), são apontadas por diversos autores como um "modelo econômico favorável para unir as dimensões ético-sociais com as dimensões ambientais da sustentabilidade".

Figura 3 - Representação dos modelos econômicos centralizado e distribuído
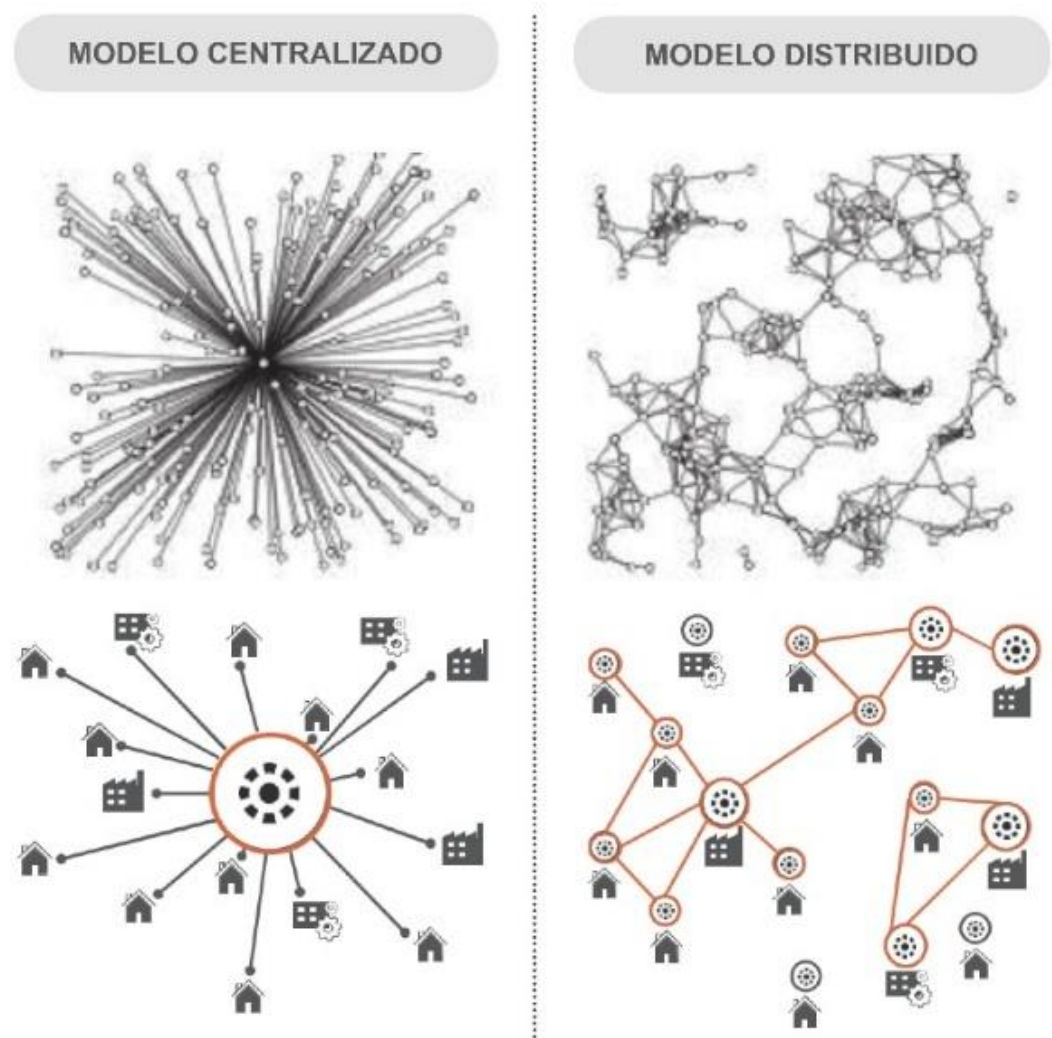

Fonte: Adaptado de LeNSin (2016) e Menichinelli (2016).

Esse modelo apresenta diversas vantagens com relação ao sistema centralizado (representado na Figura 3), atualmente o mais adotado por grandes empresas de moda e caracterizado, de acordo com o projeto LeNSin (2016), pela

\footnotetext{
${ }^{9}$ International Learning Network on Sustainability, projeto promovido pela rede LeNS (Learning Network on Sustainability). Envolvendo 36 universidades da Europa, Ásia, África, América do Sul e América Central, o foco do projeto LeNSin são os Sistemas Produto-Serviço Sustentáveis (Sustaibable ProductService Systems - S.PSS) e as Economias Distribuídas (Distributed Economies - DE). Para mais informações: <http://www.lens-international.org/>.
} 


\section{RE ARTE \\ MODA \\ DESIGN}

| http://www.revistas.udesc.br/index.php/Ensinarmode

presença de grandes unidades produtivas que entregam seus produtos através de grandes redes de distribuição, usualmente distantes do ponto de uso. As economias distribuídas são mais flexíveis que as centralizadas, pois são baseadas em unidades produtivas locais de pequena escala; permitem que a comunidade local tenha maior poder sobre os meios produtivos; possibilita que os indivíduos se conscientizem sobre questões sociais e ambientais; favorecem a conexão em rede de unidades produtivas locais, proporcionando a vantagem da escala sem a perda de flexibilidade (LeNSin, 2016; JOHANSSON; KISCH; MIRATA, 2005).

No contexto das economias distribuídas, destacam-se aqui, como mencionado anteriormente, os sistemas de design distribuído e de produção distribuída. O projeto LeNSin (2016, p. 8, tradução nossa) define um sistema de design distribuído como "um projeto aberto de design no qual uma unidade de design de pequena escala (e.g. uma pessoa/computador), sejam indivíduos, pequenos negócios e/ou comunidades locais, está conectada com outras." Segundo o projeto, o open design é uma das abordagens desse modelo.

O open design promove a participação de diversos atores, conectados em rede, no processo de desenvolvimento de produtos, em um modelo inspirado pelo open source software que envolve o compartilhamento de arquivos de projeto (no caso da moda, arquivos digitais de modelagem), com a permissão para que sejam realizadas modificações ou sejam criados projetos derivados (ABEL; EVERS; KLAASSEN, 2011; NIINIMÄKI; HASSI, 2011; STRIEN; PONT, 2016). Relevante ressaltar que, embora a prática do open design possa ser considerada antiga, uma vez que a invenção coletiva é praticada há muito tempo, o desenvolvimento e a popularização da internet e das tecnologias de comunicação proporcionaram novas perspectivas para o open design, por permitirem o rápido compartilhamento de ideias e de arquivos digitais (CABEZA, 2014; MENICHINELLI, 2016).

No modelo open design, o produto é desenvolvido globalmente, com compartilhamento e aperfeiçoamento de ideias e arquivos digitais de projeto, enquanto a produção dos artefatos desenvolvidos ocorre localmente (AVITAL, 2011; KOSTAKIS et al., 2015, 2016). O open design, portanto, é uma abordagem de design distribuído que pode favorecer a produção distribuída, definida pelo projeto LeNSin (2016, p. 7, tradução nossa) da seguinte forma: "unidade produtiva de pequena escala, no ou perto do local de uso, na qual os usuários são os produtores - sejam 
indivíduos, pequenos negócios e/ou uma comunidade local." Uma abordagem muito utilizada na produção distribuída é o uso de tecnologias de fabricação digital. Tratamse de máquinas controladas por computador capazes de interpretar arquivos de CAD ${ }^{10}$, traduzindo-os em coordenadas para a fabricação do objeto, seja por adição ou subtração de material (NEVES, 2014; GERSHENFELD, 2012).

Como promovem um modelo de economias distribuídas, o open design e a fabricação digital apresentam o potencial de reduzir os impactos causados pelo setor de moda, mas as duas estratégias, por si só, não necessariamente conduzem a um cenário mais sustentável. Por exemplo, se o usuário não tiver uma boa experiência com o processo de desenvolvimento, se ocorrerem falhas na produção do vestuário ou o processo for muito complicado, existe a possibilidade de o ciclo de vida útil do produto ser reduzido (HIRSCHER, 2013). Outra questão é a possibilidade de haver uma proliferação insustentável de artefatos em decorrência da democratização do design e do processo produtivo (RICHARDSON, 2015).

Por isso, é necessário considerar os princípios do design para a sustentabilidade desde o planejamento do projeto, de modo a auxiliar os usuários a terem um comportamento mais sustentável (NIINIMÄKI; HASSI, 2011; THACKARA, 2011; RICHARDSON, 2015). Para tal, é importante ater-se não apenas à dimensão ambiental da sustentabilidade, como também às dimensões socioética e econômica, de modo a "adotar uma abordagem holística à sustentabilidade" (VEZZOLI, 2010; GWILT, 2014, p. 22). É também recomendado iniciar o processo de design pelo mapeamento do ciclo de vida do produto a ser desenvolvido, realizando uma análise de seus impactos atuais e identificando os pontos-chave, de modo a permitir a incorporação de estratégias de sustentabilidade que auxiliem a minimizar os principais impactos identificados, cuidando para não criar efeitos colaterais em outras etapas do ciclo de vida do produto (GWILT, 2014).

No que se refere à preparação do designer para trabalhar em projetos de open design, é necessário considerar, em primeiro lugar, a mudança na relação entre designers e usuários, uma vez que a fronteira entre esses papeis se dilui (HUMMELS, 2011; THACKARA, 2011; FERRONATO; FRANZATO, 2015). A principal função do designer de moda, nesta abordagem, é a de facilitador (MUL, 2011; FERRONATO;

${ }^{10}$ CAD é a sigla correspondente a Computer-Aided Design (Projeto Assistido por Computador), ou seja, o uso de softwares para auxiliar os processos de design produção. 
FRANZATO, 2015). Ao invés de desenvolver um produto já finalizado, o designer cede as ferramentas aos usuários, define as condições para o processo de interação e incentiva os usuários a tornarem-se cocriadores e produtores dos próprios produtos (MUL, 2011; FERRONATO; FRANZATO, 2015; STRIEN; PONT, 2016).

Devido a essas mudanças, Hummels (2011) acredita ser necessária a adoção de um modelo educacional especificamente favorável para o open design, que reflita sobre seus próprios paradigmas e imagine que tipo de designers a sociedade precisará no futuro. Segundo a autora, o ensino de design para o open design poderia se beneficiar dos métodos de aprendizagem ativa e contextualizada.

Um desses métodos, apontado por Moura e Barbosa (2013, p. 21), são os projetos educacionais, ou seja, um empreendimento com "a finalidade de realizar ações voltadas para a formação humana, construção do conhecimento e melhoria de processos educativos". Dentre as diferentes categorias de projetos educacionais, os projetos de aprendizagem são aqueles desenvolvidos "por alunos durante uma (ou mais) disciplina(s), sob orientação de um professor" (Ibidem, p. 25).

A aprendizagem ativa e contextualizada ocorre por meio da elaboração de projetos de aprendizagem relacionados a uma situação próxima do real e que envolvam aprender por meio da ação, permitindo que o discente tenha maior interação com o assunto em estudo e construa o conhecimento, ao invés de recebê-lo de forma passiva (BARBOSA; MOURA, 2013; PAZMINO, 2014).

Na perspectiva de Heller e Tallarico (2016), projetos de ensino em design bem-sucedidos são aqueles que desafiam os alunos, oferecendo variáveis e incertezas o suficiente para estimulá-los a irem além das soluções rasas, proporcionando conhecimento, compreensão e sabedoria. Segundo os autores:

Frequentemente, os estudantes dizem que bons trabalhos lhes dão a confiança para pensar em soluções para problemas aparentemente insolúveis ou para abandonar suas zonas de conforto e praticar o design em situações em que a ausência de controle absoluto é um requisito (Ibidem, p. 20).

Essa última característica é especialmente importante para o ensino voltado ao open design, de acordo com Hummels (2011), pois os estudantes de design devem aprender a abraçar a ambigüidade, a abertura e a experimentação. A autora também reforça a necessidade de promover, entre os discentes, atitude voltada para a colaboração, visto que no open design é essencial cooperar com os usuários e com outros especialistas em equipes multidisciplinares. 


\section{RE ARTE \\ MODA \\ DESIGN}

Já para a utilização de tecnologias de fabricação digital, é essencial desenvolver habilidades técnicas específicas. Contudo, como revela a pesquisa realizada por Bastos (2014, p. 123), "os profissionais da área da moda desconhecem as possibilidades da fabricação digital", embora demostrem interesse ou curiosidade. Mesmo designers envolvidos com fabricação digital no setor de vestuário, segundo a pesquisadora, não apresentam todo o conhecimento técnico necessário (uso de equipamentos e softwares), pois a educação em design de moda não considera, atualmente, as tecnologias de fabricação digital. De maneira geral, as máquinas de fabricação digital e os softwares utilizados (vetoriais, de modelagem 3D e para uso das máquinas) não são comuns ao setor de vestuário (BASTOS, 2014).

Os espaços dedicados ao uso e ao compartilhamento de tecnologias de fabricação digital, chamados makerspaces, também precisam se adaptar para receber indivíduos envolvidos com moda. Nesses ambientes, os profissionais de moda entrevistados por Bastos (2014) reportaram sentir falta de equipamentos específicos para a produção de vestuário, como máquinas de costura industrial e de estamparia e de bordado digital. De modo semelhante, os espaços de compartilhamento de equipamentos de confecção de vestuário - os cosewings, como indica Hirscher (2013) - normalmente não possuem tecnologias de fabricação digital. Portanto, é necessário promover maior interação entre moda e fabricação digital, com compartilhamento de conhecimento entre os indivíduos envolvidos com ambos e adequação de espaços e equipamentos.

\subsection{Desenvolvimento dos artefatos}

O projeto de aprendizagem envolveu 15 alunos do $3^{\circ}$ e $4^{\circ}$ ano do curso de graduação em Design de Produto, matriculados na disciplina eletiva Design de Moda para a Sustentabilidade, os quais dividiram-se em quatro trios e uma dupla para o desenvolvimento do trabalho. Do total de alunos, apenas quatro (27\%) já haviam estudado moda anteriormente por meio de cursos livres ou técnicos; três pessoas $(20 \%)$ sabiam costurar, das quais duas (13\%) tinham conhecimentos sobre modelagem, enquanto outros quatro alunos $(26 \%)$ sabiam fazer trabalhos manuais como bordado, crochê ou tricô.

Devido ao pouco contato que a maioria dos alunos teve com processos produtivos de moda, eles realizaram uma atividade prática de construção de vestuário 
antes da realização do projeto, a qual objetivou familiarizá-los com os materiais têxteis e os processos de modelagem e costura. Como o Departamento de Design da UFPR não é equipado com itens necessários ao design de moda, como máquinas de costura e manequins de modelagem, essa atividade foi realizada na escala 1:2, com auxílio de um manequim em escala pertencente a um dos docentes, e os alunos que não tivessem acesso a uma máquina poderiam realizar a costura à mão.

Como o projeto de aprendizagem teve como referência The Post-Couture Collective, cujas peças são projetadas para serem montadas sem uso de máquinas de costura, a falta deste equipamento no Departamento de Design não foi um obstáculo para a realização do projeto, uma vez que esta característica do empreendimento foi mantida, assim como o uso da tecnologia de corte a laser.

A primeira etapa de desenvolvimento, de pesquisa e planejamento, foi realizada em conjunto pelas cinco equipes, com liderança dos docentes. Nessa fase, os dados foram coletados por meio de entrevista via videoconferência ${ }^{11} \mathrm{com}$ o fundador da marca, Martijn Van Strien, e pesquisa documental a partir de matérias online, do site da marca e de suas redes sociais ${ }^{12}$.

Também foi analisado um artefato da marca, cujo arquivo digital foi adquirido para ser construído em conjunto pelos participantes da pesquisa. Para a realização desta atividade de teste do produto, um obstáculo foi encontrar empresas prestadoras de serviços de corte a laser aptas e dispostas a trabalhar com tecido. Cabe observar que a peça foi cortada e montada em neoprene de um milímetro de espessura, pois este era o tecido mais próximo ao utilizado por The Post-Couture Collective à venda em lojas de varejo de tecido. Contudo, a marca utiliza, em seus protótipos, tecidos de dois ou três milímetros de espessura. Talvez por essa diferença, os encaixes da camiseta montada não ficaram tão firmes quanto deveriam, desprendendo-se conforme o movimento do usuário.

O planejamento teve início com a análise do ciclo de vida dos produtos de The Post-Couture Collective e de seu desempenho com relação a contribuições para a sustentabilidade. Para analisar o desempenho, foi preenchido um check-list contemplando todos os princípios, e correspondentes diretrizes, das três dimensões

\footnotetext{
${ }^{11}$ Realizada previamente, no dia 27 de junho de 2016, com duração de meia hora.

12 Website da marca: <http://www.postcouture.cc/>; redes sociais: <facebook.com/postcouture>; $<$ facebook.com/groups/thepostcouturecommunity/>; <instagram: instagram.com/postcouture/>; $<$ twitter.com/PostCouture >; <vimeo.com/martijnvanstrien>. 
do design para a sustentabilidade, apontados por Manzini e Vezzoli (2008) e Vezzoli (2010). A partir do check-list, foram gerados diagramas de radar para cada dimensão, que auxiliaram na visualização dos resultados obtidos.

Com base nessa análise, os próprios alunos identificaram dois princípios para serem priorizados em cada dimensão da sustentabilidade, a saber:

- dimensão ambiental: minimizar o uso de recursos e otimizar a vida dos produtos;

- dimensão social: favorecer/integrar o fraco/marginalizado e capacitar/promover o consumo sustentável/ responsável;

- dimensão econômica: fortalecer/valorizar os recursos locais e respeitar/valorizar a cultura local.

O ciclo de vida do produto foi planejado a partir dessas diretrizes, com indicação de estratégias que poderiam ser adotadas em cada etapa para atender aos princípios selecionados e reduzir os impactos então gerados. Embora o foco do projeto fossem os artefatos em si, o exercício de planejamento do ciclo de vida considerou, também, o sistema no qual o produto estaria inserido.

Com base nesse exercício, foram estabelecidas as diretrizes de projeto (Quadro 1), que consideram princípios de sustentabilidade, além de questões práticas e estéticas do produto. Quanto ao dimensionamento da coleção, foi decidido que cada equipe deveria criar ao menos um look completo, que poderia ser um vestido ou uma saia e blusa, por exemplo.

Quadro 1 - Diretrizes do projeto

\section{PRODUTO:}

- permitir customização;

- apresentar multifuncionalidade e diversidade de estilos/configurações;

- minimizar o consumo de material e de energia;

- integrar elementos da cultura local.

\section{SERVIÇOS:}

- preparar modelagens para download;

- elaborar instruções detalhadas para montagem (passo-a-passo);

- fornecer instruções de uso e customização.

\section{TECNOLOGIAS:}

- utilizar corte a laser;

- desenvolver moldes com no máximo 1,40m X 1,0m (tamanho da cortadora a laser utilizada);

- preparar arquivos para corte em software de desenho vetorial;

- não utilizar tecidos planos de fibras naturais (as bordas desfiam após o corte a laser);

- ser fácil de montar (possibilitar DIY e produção local) e desmontar (permitir novas configurações);

- ser produzido sem costura à máquina;

- integrar técnicas artesanais.

Fonte: Os autores (2017). 


\section{RE ARTE \\ MODA \\ DESIGN}

As etapas seguintes do processo de desenvolvimento do vestuário foram conduzidas separadamente pelas equipes, seguindo instruções fornecidas pelos docentes. A síntese envolveu a seleção de um conceito e de um tema, a partir de pesquisa de macrotendências de moda. As equipes também desenvolveram moodboards de estilo, do qual extraíram a cartela de cores e as formas e estruturas para direcionar a geração de alternativas. Foi recomendado, ainda, que as equipes realizassem pesquisa de materiais, texturas, técnicas e tecnologias, como referência para a criação de soluções.

Cada equipe reuniu todas essas informações em uma ficha-síntese, cujo modelo foi fornecido pelos docentes. A elaboração de uma ficha-síntese é sugerida por Cardoso e Demarchi (2012) para facilitar a comunicação entre os diversos atores envolvidos no processo de desenvolvimento. Esse documento, segundo as autoras, apresenta uma visão geral do projeto, contendo todas as informações referentes às fases de planejamento e síntese.

A terceira etapa do projeto teve início com a geração de alternativas para o encaixe das peças, utilizando tecido e papel. Já as alternativas de vestuário foram desenvolvidas por meio de esboços e construção de protótipos em miniatura ou em tamanho real. Uma das equipes utilizou um manequim de modelagem nesta fase, mas outros alunos, na falta de um manequim apropriado, mostraram criatividade para aproveitar diferentes objetos com o intuito de simular o corpo humano.

Durante a geração de alternativas, os alunos de modo geral não exploraram a possibilidade de utilizar o corte a laser para criar intervenções na modelagem ou na superfície têxtil. Devido ao elevado custo de corte a laser, constatado durante a construção de uma peça de The Post-Couture, considerou-se necessário utilizar a tecnologia com fins além do corte dos moldes em si, pois, caso o corte fosse simples e pudesse ser realizado manualmente, o usuário poderia não se sentir motivado a recorrer ao corte a laser. Desse modo, os docentes incentivaram as equipes a explorar mais as possibilidades estéticas do corte a laser.

$\mathrm{Na}$ etapa de seleção e elaboração, as alternativas geradas foram selecionadas e as equipes aprimoraram a ideia inicial. Foram elaboradas as modelagens e algumas equipes fizeram protótipos antes de cortar os produtos finais. Nesta fase, duas equipes precisaram alterar consideravelmente a proposta inicial por 


\section{RE ARTE MODA DESIGN}

dificuldades encontradas para a elaboração das modelagens e para permitir o encaixe dos moldes na cortadora a laser.

Após construídas as peças, foram realizadas fotos dos produtos e elaborados os manuais de instrução, contendo vídeos, ilustrações e fotografias. Esses manuais contemplaram desde a construção das peças em si, até alternativas de uso e possibilidades de customização.

\subsection{Artefatos resultantes}

O primeiro produto apresentado foi denominado por sua equipe como feé, uma abreviação da palavra feérico (Figura 4). Esse trabalho destaca-se pela modelagem zero waste, com aproveitamento integral do tecido, pela versatilidade de uso e pela possibilidade de ajustes das peças - uma saia e uma blusa modulares, que podem ser utilizadas separadamente ou conectadas para formar um vestido. Na saia, a equipe acrescentou recortes decorativos, elaborados a partir do desenho do bolso que será nela encaixado. Para aumentar as possibilidades de personalização, são apresentadas duas opções de desenho para escolha do usuário, que pode bordar livremente a saia a partir dos pontos em que se encontram os recortes.

Figura 4 - Resultados equipe feé.
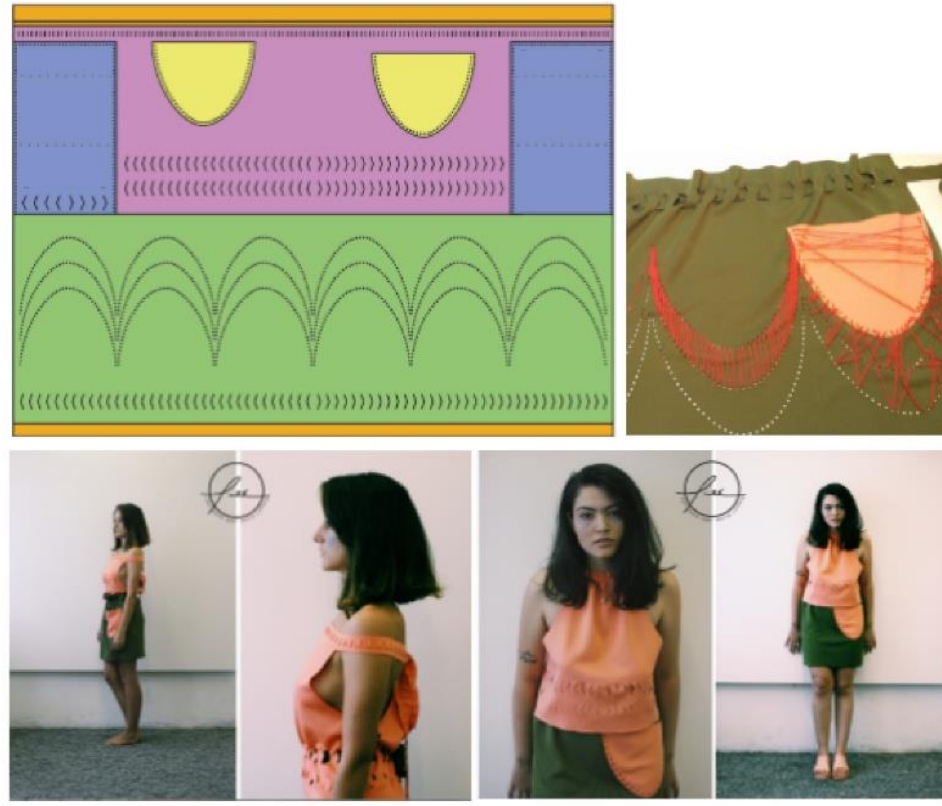

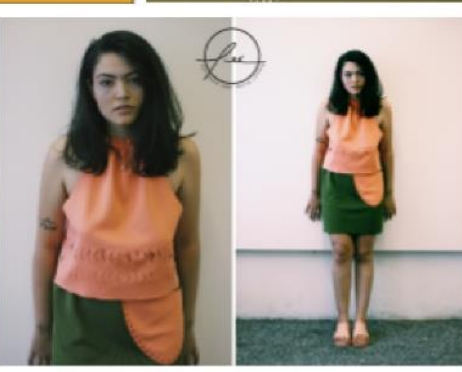

Fonte: Autora (2017)

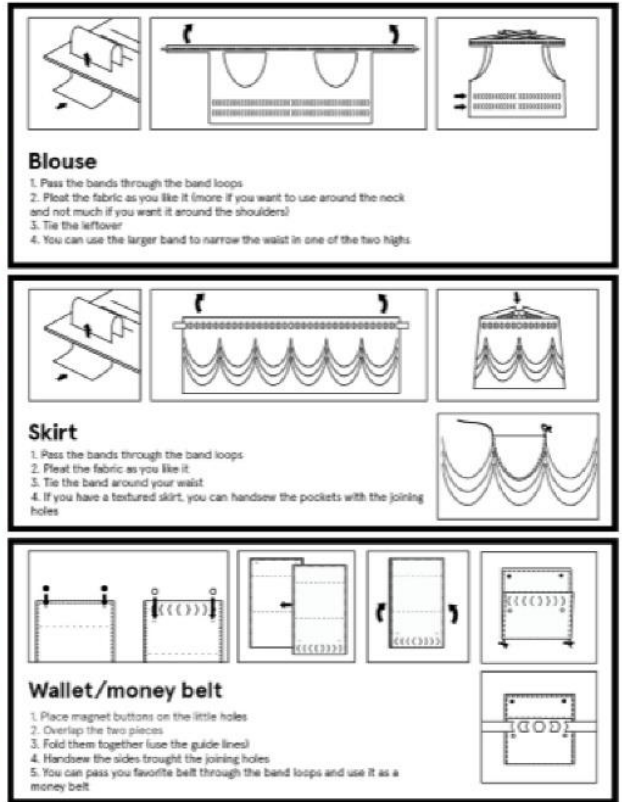




\section{RE ARTE \\ MODA \\ DESIGN}

Já o trabalho "Nöda" destacou-se por explorar bordado manual e fitas termocolantes para a união das partes. A equipe elaborou uma saia, uma blusa e um casaco estilo quimono. Cada uma foi produzida em um tecido diferente. $\mathrm{O}$ bordado aplicado no casaco e na blusa foi desenhado por uma das integrantes da equipe, podendo ser aplicdo sobre as peças por meio de termocolante, como ilsutra a Figura 5. A equipe indica que o bordado poderia ser vendido pronto, junto com um kit de construção, ou poderia ser disponibilizado o desenho para ser replicado por uma bordadeira local ou por uma máquina de bordado digital.

Figura 5 - Resultados equipe Nöda.
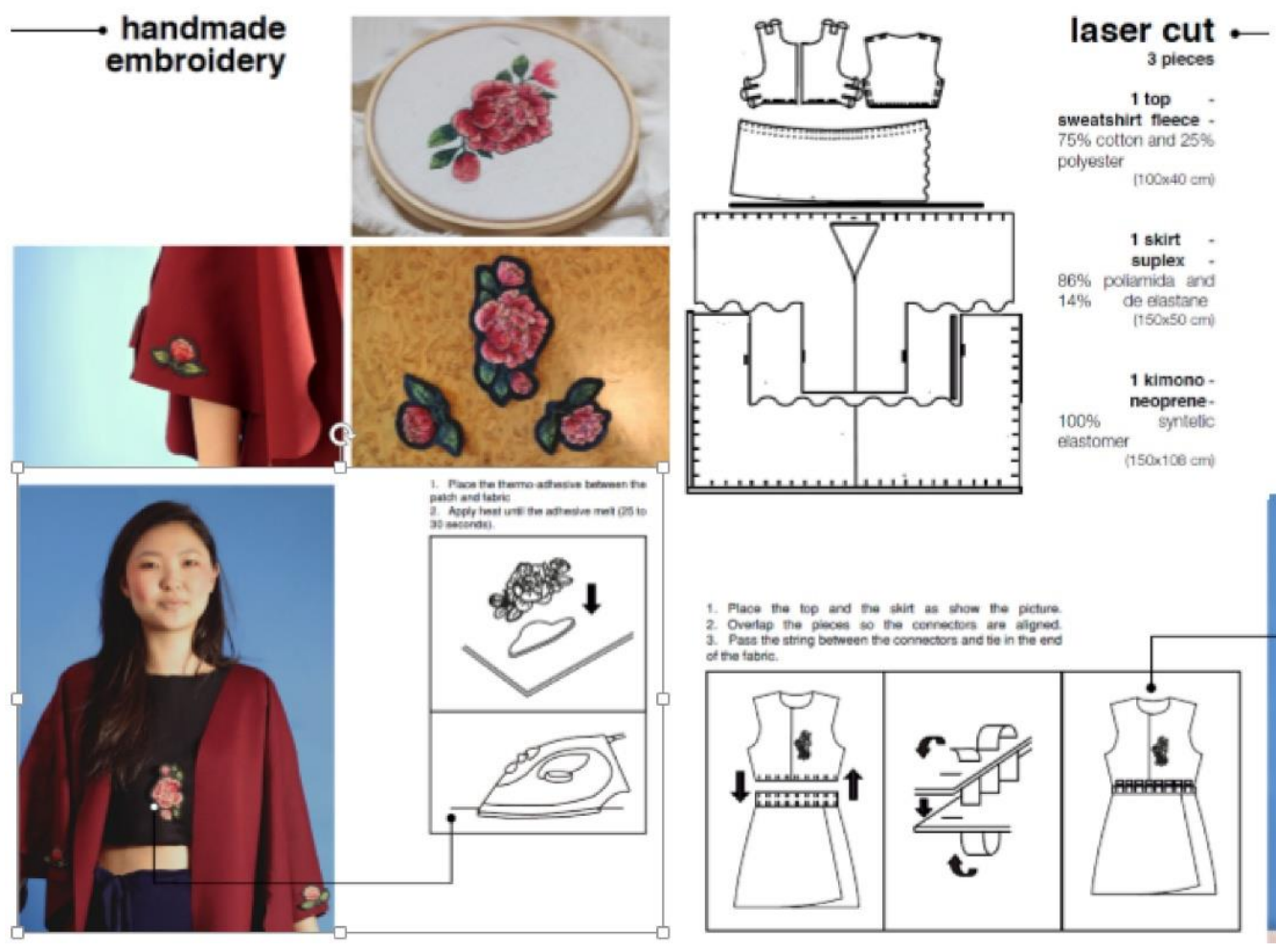

polyester

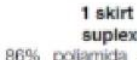

$14 \%$ poliarnicta and

$14 \%$ de elastane
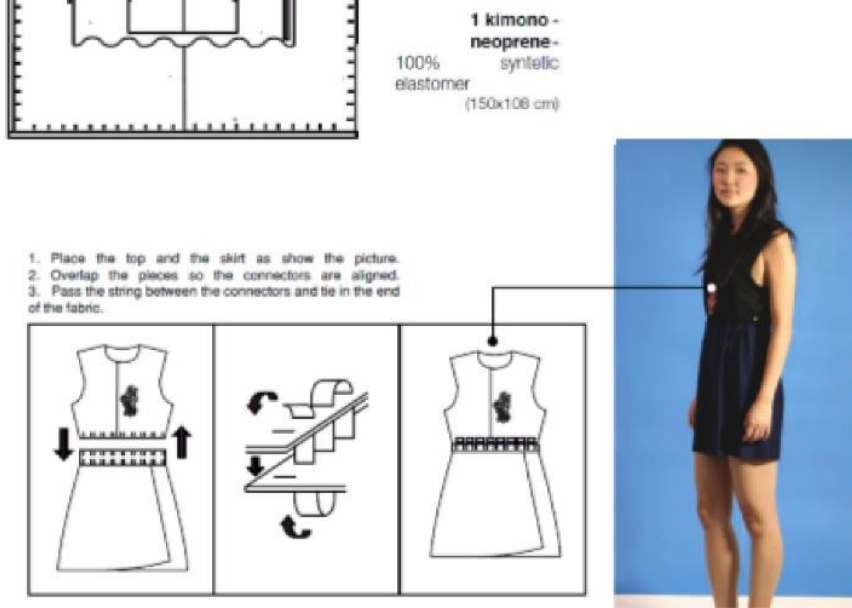

Fonte: Autora (2017).

O terceiro trabalho, denominado Sulco, procurou aproximar o open design e a tecnologia digital do usuário. Para isso, a equipe selecionou como mecanismo de união uma técnica que faz parte do dia-a-dia de muitas pessoas: a amarração de cadarço (ver Figura 6). Foram projetadas uma saia e uma blusa com mangas compridas removíveis, ambos elaborados em neoprene. 


\section{RE ARTE \\ MODA \\ DESIGN}

| http://www.revistas.udesc.br/index.php/Ensinarmode

Figura 6 - Resultados equipe Sulco
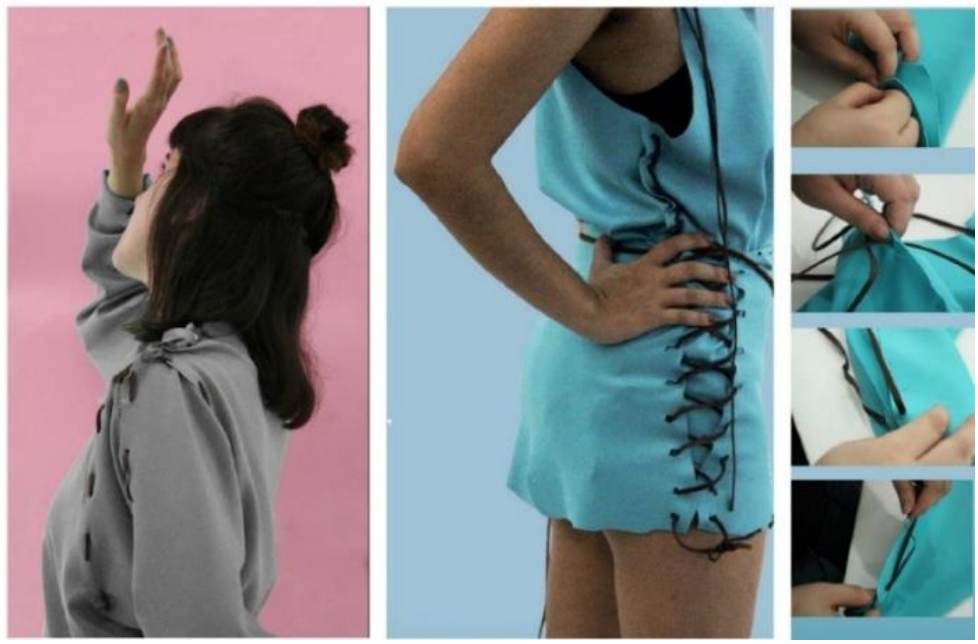

Fonte: Autora (2017)

Nouveau é o nome do quarto trabalho. As modelagens desenvolvidas são simples e aproveitam toda a extensão do tecido, sendo os produtos confeccionados a partir de retângulos de tecido por meio de amarrações, o que permite a multifuncionalidade das peças.

O quinto trabalho foi nomeado LEC. A peça elaborada apresenta modelagem simples e uso versátil, como retratado na figura 7 . Foram realizados cortes vazados na barra e no decote para explorar melhor a tecnologia do laser. Os únicos resíduos gerados no corte são do decote e das cavas. A modelagem forma uma peça única, reduzindo a quantidade de conexões a serem feitas.

Figura 7 - Resultado equipe LEC

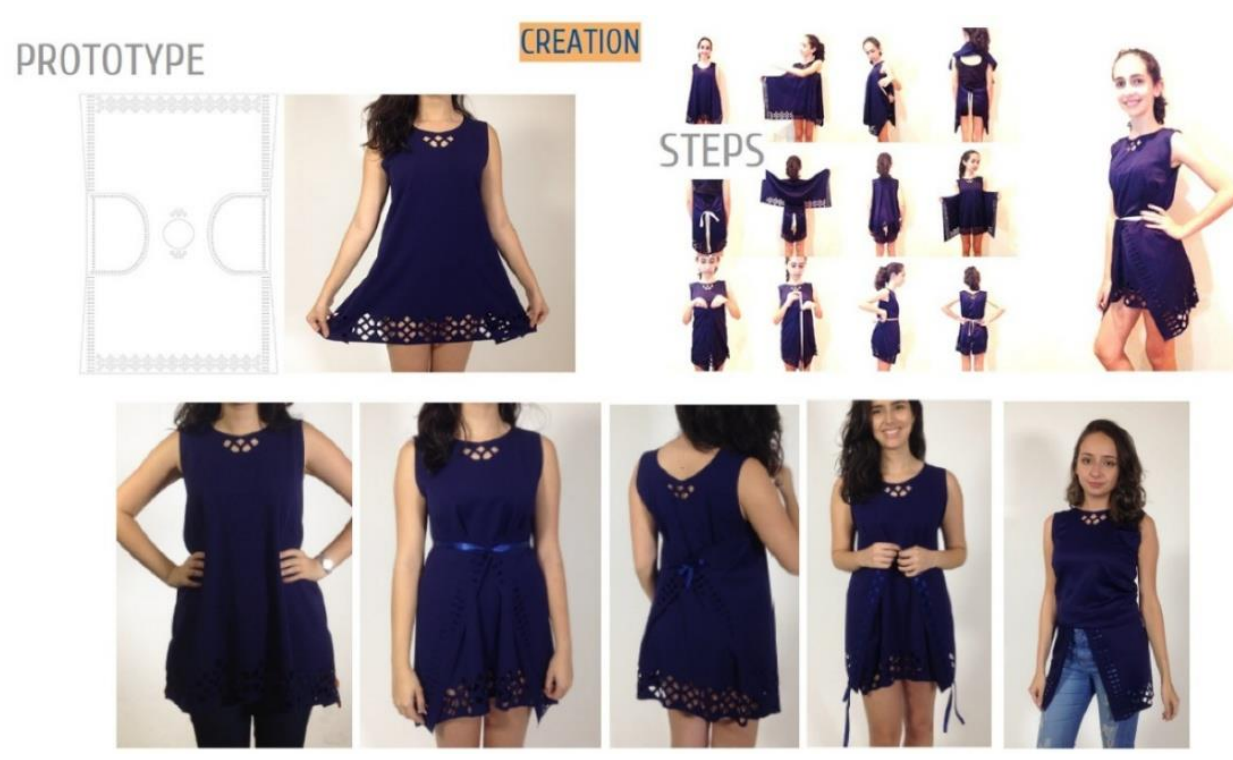

Fonte: Autora, 2017. 
A equipe identificou sete configurações possíveis para a mesma roupa e desenvolveu um passo a passo, com fotografias, para auxiliar o usuário a obter essas configurações. Também foram elaboradas fotografias para mostrar as possibilidades de customização por meio do uso de fitas coloridas nas bordas do vestido. Um destaque desse trabalho foi ter sido projetado o pós-uso do vestido, que pode ser dobrado e amarrado para formar uma bolsa.

\section{DISCUSSÃO}

A revisão bibliográfica revelou haver poucas publicações, no Brasil, que relacionem moda com open design e fabricação digital. A busca por teses e dissertações mostra um progressivo crescimento de publicações sobre as duas temáticas desde 2013. Contudo, dos 11 trabalhos encontrados, apenas três tem como foco a moda. Com relação aos artigos científicos nacionais identificados, é notável a prevalência de publicações sobre tecnologias de fabricação digital (dez artigos, os quais enfatizam sobretudo a estamparia digital, em primeiro lugar, e a impressão 3D, em segundo) em detrimento do open design. Foi encontrado apenas um artigo brasileiro de moda que tinha como temática principal o open design, enquanto outros três apenas tangenciavam esse tema.

Os resultados de publicações internacionais revelaram mais trabalhos que relacionam moda e open design, em detrimento dos que relacionavam a área às tecnologias de fabricação digital. Ainda assim, há prevalência, dentre as obras internacionais encontradas, de publicações sobre open design e sobre fabricação digital com ênfase no design de produto sem considerações à moda.

Esse resultado revela uma lacuna teórica a ser preenchida. Para tanto, considerando a natureza do open design e da fabricação digital, é necessário o desenvolvimento de pesquisas aplicadas. Do mesmo modo, é importante preparar os designers para atuarem sob estes novos paradigmas projetuais e produtivos por meio da prática, como explicitado por Hummels (2011), o que envolve métodos de aprendizagem ativa e contextualizada, como é o caso dos projetos de aprendizagem, utilizado na pesquisa aqui relatada.

Como esse tipo de aprendizagem envolve a elaboração de projetos práticos em uma situação próxima do real, optou-se como estratégia educativa o desenvolvimento 
de vestuário para uma empresa já existente - The Post-Couture Collective. Embora os produtos resultantes não tenham sido efetivamente comercializados pela empresa, a possibilidade de obter feedback de seu fundador, assim como de ter os seus trabalhos publicados no blog da marca ${ }^{13}$, com alcance internacional, foi um importante estímulo para os discentes durante o projeto, além de resultar em uma experiência gratificante.

Desenvolver um produto de vestuário foi um grande desafio para a maioria dos alunos, já que poucos possuíam conhecimentos prévios em design de moda, modelagem e construção de roupas. Ainda que não fosse necessário costurar, alguns grupos tiveram dificuldade em materializar suas ideias no momento de desenvolver as modelagens. A superação destes alunos para a finalização de seus trabalhos foi destacada por uma das especialistas que participaram da avaliação.

Com relação ao processo de desenvolvimento dos produtos, optou-se por adotar como referência processos convencionais de design de moda para que os alunos de Design de Produto tivessem contato com a dinâmica do design de moda. Contudo, foram necessárias adaptações que permitissem a inserção de ferramentas de design para a sustentabilidade, além de adequações referentes às particularidades do open design e da fabricação digital.

Todas as etapas do processo foram seguidas na mesma sequência e apenas duas etapas sofreram alterações significativas: o planejamento, devido à inserção de ferramentas para considerar os princípios do design para a sustentabilidade e projetar o ciclo de vida do produto; e a elaboração, quando é necessário utilizar tecnologias diferentes e desenvolver material de apoio, como os manuais de construção. Durante o desenvolvimento e apresentação final do projeto, a ficha-síntese mostrou-se um recurso importante para a comunicação do processo criativo.

No planejamento, as ferramentas de check-list, diagramas de radar e análise do ciclo de vida do produto mostraram-se eficazes para considerar questões de sustentabilidade relacionadas às suas três dimensões, assim como para identificar aspectos que mereciam mais atenção para tornar os produtos de The Post-Couture mais sustentáveis. Na etapa de síntese, o uso dessas ferramentas facilitou a definição das diretrizes de projeto.

\footnotetext{
${ }^{13}$ Disponível em: <http://www.postcouture.cc/news-backend/2017.2.26.24022017-post-couture-
} brasil>. 


\section{RE ARTE \\ MODA \\ DESIGN}

Como todos os alunos envolveram-se na análise e nas decisões projetuais, não demonstraram resistência para seguir as diretrizes estabelecidas, embora tenham relatado, ao final do projeto, que trabalhar com um número tão grande de diretrizes foi desafiador. Cabe retomar, neste aspecto, a afirmação de Heller e Tallarico (2016) de que projetos de aprendizagem de design bem-sucedidos desafiam os alunos, estimulando-os a irem além das soluções rasas.

O resultado dos produtos desenvolvidos confirma isso. Uma das especialistas consultadas destacou, por exemplo, que todas as equipes conseguiram superar as técnicas utilizadas, a saber, fabricação digital e o uso mecanismos de conexão sem costura à máquina. Já Martijn van Strien, fundador de The Post-Couture enfatizou dois aspectos presentes em todos os projetos: a exploração da adaptabilidade das peças, em termos de ajustes e customização, e a integração de técnicas artesanais locais. Segundo Strien, essas são questões ainda não exploradas por The Post-Couture que necessitam de mais investigação.

O designer fez apenas uma ressalva, com relação aos materiais utilizados. Strien notou que todas as equipes selecionaram o neoprene, um tecido sintético, de fontes não renováveis. Questionou se não poderiam ser utilizados materiais locais. Essa foi, de fato, uma limitação encontrada durante o desenvolvimento: a disponibilidade de materiais sustentáveis no varejo e a compatibilidade dos materiais com o corte a laser.

Outra limitação foi o tamanho da máquina de corte a laser utilizada. Três equipes necessitaram fazer ajustes, e até mesmo modificar a proposta ao final da etapa de elaboração, para que os moldes se adequassem ao tamanho do equipamento. Percebe-se, portanto, a necessidade de começar o projeto a partir da modelagem, tendo em mente o tamanho da cortadora.

Ainda com relação ao corte a laser, a dificuldade para encontrar uma empresa ou espaço apto a cortar tecido corrobora a pesquisa de Bastos (2014), a qual apontou a necessidade de os espaços dedicados à fabricação digital adequarem-se para atender indivíduos envolvidos com moda. Contudo, o empresário que prestou o serviço de corte a laser para o projeto mostrou-se disposto a acolher os alunos e prestar todos os esclarecimentos necessários sobre a tecnologia e a preparação dos arquivos digitais, demonstrando que uma alternativa para a capacitação de estudantes 
e profissionais de moda em fabricação digital é possível por meio da troca de conhecimento com profissionais já envolvidos com essas tecnologias.

Esse fator reforça outro aspecto importante, apontado por Hummels (2011): a necessidade de promover a atitude voltada para a colaboração com outros especialistas e com os usuários. Como o projeto não chegou a ser disponibilizado para o público, os alunos não chegaram a interagir com usuários, mas consideraram e previram a sua participação na cocriação do produto por meio dos atos de customizar ou mesmo de vestir a peça, quando o usuário poderia escolher uma entre diversas configurações possíveis. Isso revela que, de fato, os alunos abraçaram a abertura, abrindo precedentes para que seus produtos assumam novas formas, não previstas inicialmente por seus criadores.

Algumas das estratégias utilizadas pelos alunos para proporcionar abertura, permitindo e facilitando o envolvimento do usuário, foram: modularidade, multifuncionalidade, mecanismos de ajuste e customização, proporcionada sobretudo pela interação entre recortes a laser e fitas ou linhas de bordado.

Apesar dos bons resultados obtidos, reforçados pelos especialistas consultados, alguns aspectos merecem atenção. O corte a laser, de acordo com uma das especialistas, poderia ter sido mais explorado para a criação de intervenções no vestuário, deixando-o em evidência. A mesma consideração foi realizada quanto à inserção de técnicas artesanais, que poderiam ter tido maior destaque na opinião de dois dos especialistas.

\section{CONSIDERAÇÕES FINAIS}

Ministrar a primeira disciplina de moda do programa de graduação em design da Universidade Federal do Paraná foi um desafio para os docentes, assim como o projeto de aprendizagem proposto foi desafiador para os discentes. Propor a abordagem do open design e a utilização de tecnologias de fabricação digital permitiu trabalhar com design para a sustentabilidade sob uma perspectiva diferente da usualmente adotada. Também proporcionou a construção de conhecimento sobre a aplicação de ambos no design e na produção de vestuário mais sustentável.

A realização de um projeto de aprendizagem, com envolvimento ativo dos alunos em um contexto próximo ao real, mostrou-se um método de ensino eficaz, 
apropriado especialmente para capacitar os alunos para a atuação com open design e com tecnologias de fabricação digital.

O ensino do processo de design de moda, no contexto estudado, não diferiu muito do ensino de processos convencionais, como abordado na discussão, pois foram necessárias apenas pequenas adaptações. Na etapa de planejamento, é recomendado adotar ferramentas de design para a sustentabilidade que permitam analisar impactos e projetar o ciclo de vida do produto, familiarizando os alunos com estes recursos e incluindo-os no processo de definição das diretrizes projetuais.

$\mathrm{Na}$ etapa de síntese, é importante pesquisar referências técnicas e tecnológicas que revelem possibilidades de exploração do open design e das tecnologias de fabricação digital. Pode-se elaborar um moodboard com essas referências, que servirão de inspiração durante a geração de alternativas, quando um aspecto determinante é a experimentação de diferentes métodos de união.

Outro fator que merece atenção são as possibilidades e limitações da tecnologia utilizada, que devem ser investigadas por meio do contato direto com especialistas em fabricação digital. Entender como o equipamento funciona e o que é possível, ou não, fazer com ele é determinante para o resultado final. Esses fatores técnicos devem ser considerados quando da seleção de alternativas e elaboração dos arquivos digitais de modelagem.

Destaca-se também a necessidade de incentivar o uso de estratégias projetuais que proporcionem abertura e o envolvimento do usuário. Embora essa abordagem não tenha sido adotada no projeto aqui relatado, o envolvimento do usuário ainda nas etapas iniciais de planejamento, abrindo espaço para a cocriação, é algo a ser considerado. A interação direta com usuário permitirá que o aluno desenvolva a capacidade de colaborar não apenas com outros designers ou profissionais especializados, mas também com indivíduos não familiarizados com os processos criativo e produtivo, o que o tornará mais empático e apto a desenvolver soluções que de fato permitam o envolvimento do usuário na elaboração de produtos cujos moldes foram adquiridos online.

Cabe ainda ressaltar a importância de fornecer feedback constante durante o desenvolvimento do projeto de aprendizagem, reconhecendo os avanços dos discentes e estimulando-os a ir além e explorar mais os recursos disponíveis. 


\section{RE ARTE \\ MODA \\ DESIGN}

Com essas recomendações e observações, espera-se que mais docentes de programas de graduação em moda e em design explorem o open design e a fabricação digital para o desenvolvimento de produtos de moda, capacitando seus alunos para atuarem em contextos emergentes de criação e produção que promovam a sustentabilidade do setor de vestuário e permitam o empoderamento do usuário.

\section{REFERÊNCIAS}

ABEL, B. van; EVERS, L.; KLAASSEN, R. Preface. In: ABEL, B. van Abel; Klaassen, R.; Evers, L.; Troxler, P. (Eds.). Open Design Now: Why Design Cannot Remain Exclusive. Amsterdam: BIS publishers, 2011. Disponível em: <http://opendesignnow.org/index.html?p=38.html>. Acesso em: 19 nov. 2016.

AVITAL, M. The generative bedrock of open design. In: ABEL, B. van; KLAASSEN, Roel; EVERS, Lucas; TROXLER, Peter (Eds.). Open Design Now: why design cannot remain exclusive. Amsterdam: BIS publishers, 2011. Disponível em: <http://opendesignnow.org/index.html?p=405.html>. Acesso em: 19 nov. 2017.

BASTOS, V. F. Moda e fabricação digital em um contexto Fab Lab: equipamentos, métodos e processos para o desenvolvimento de produtos. $151 \mathrm{f}$. Dissertação (Mestrado em Design) - Centro de Artes e Comunicação, Universidade Federal de Pernambuco, Recife, 2014.

BORGES, M. D. E. S. Problematizando a formação superior em Moda. dObra[s], v. 10, n. 21, 2017

CABEZA, E. U. R. Open Design no cenário contemporâneo. 169 f. Dissertação (Mestrado em Design) - Faculdade de Arquitetura, Artes e Comunicação, Universidade Estadual Paulista, Bauru, 2014.

CARDOSO, M. X.; DEMARCHI, A. P. P. O Processo de Desenvolvimento de Produtos de Moda baseado no Design Thinking: um estudo de caso. Projética, Londrina, v. 3, n. 2, p. 51-65, 2012.

CONFORTO, E. C.; AMARAL, D. C.; SILVA, S. L. DA. Roteiro para revisão bibliográfica sistemática: aplicação no desenvolvimento de produtos e gerenciamento de projetos. Trabalho apresentado no $8^{\circ}$ Congresso Brasileiro de Gestão de Desenvolvimento de Produto, Porto Alegre, 2011.

DRESCH, Aline; LACERDA, Daniel Pacheco; ANTUNES JÚNIOR, José Antônio Valle. Design Science Research: método de pesquisa para avanço da ciência e tecnologia. Porto Alegre: Bookman, 2015.

FERRONATO, P. B.; FRANZATO, C. Open Design e Slow Fashion para a Sustentabilidade do Sistema Moda. Modapalavra E-periódico, Florianópolis, v. ano 9, edição especial, p. 104-115, 2015. 
GERSHENFELD, N. How to Make Almost Anything: The Digital Fabrication Revolution. Foreign Affairs, Tampa, nov.-dez. 2012. Disponível em: <https://www.foreignaffairs.com/articles/2012-09-27/how-make-almost-anything>. Acesso em: 19 nov. 2016.

GWILT, Alison. Producing sustainable fashion: the points for positive intervention by the fashion designer. In: GWILT, Alison; RISSANEN, Timo (Eds.). Shaping sustainable fashion: changing the way we make and use clothes. Londres: Earthscan, 2011.

Moda sustentável: um guia prático. Traduzido por: LONGARÇO, M. São Paulo: Gustavo Gili, 2014. Título original: A practical guide to sustainable fashion.

HELLER, Steven; TALARICO, Lita. Escola de design: projetos desafiadores de escolas do mundo todo. São Paulo: Editora Senac, 2016.

HIRSCHER, A.-L. Fashion Activism Evaluation and Application of Fashion Activism Strategies to Ease Transition Towards Sustainable Consumption Behaviour. Research Journal of Textile and Apparel, v. 17, n. 1, p. 23-38, 2013.

HUMMELS, C. Teaching attitudes, skills, approaches, structure and tools. In: ABEL, B. van Abel; Klaassen, R.; Evers, L.; Troxler, P. (Eds.). Open Design Now: Why Design Cannot Remain Exclusive. Amsterdam: BIS publishers, 201. Disponível em: <http://opendesignnow.org/index.html?p=19.html>. Acesso em: 19 nov. 2016.

JOHANSSON, A.; KISCH, P.; MIRATA, M. Distributed economies - A new engine for innovation. Journal of Cleaner Production, v. 13, n. 10-11, p. 971-979, 2005.

KOSTAKIS, Vasilis; NIAROS, Vasilis; DAFERMOS, George; BAUWENS, Michel. Design global, manufacture local: Exploring the contours of an emerging productive model. Futures, v. 73, p. 126-135, 2015.

KOSTAKIS, Vasilis; LATOUFIS, Kostas; LIAROKAPIS, Minas; BAUWENS, Michel. The convergence of digital commons with local manufacturing from a degrowth perspective: two illustrative cases. Journal of Cleaner Production, in press, p. 1-10, 2016.

LeNSin - INTERNATIONAL LEARNING NETWORK ON SUSTAINABILITY. The LeNSin research hypothesis: the design of S.PSS applied to DE: win-win offer model for a sustainable development for all. Milão: Politecnico di Milano - Design dept, 2016. Relatório de pesquisa.

MANZINI, Ezio; VEZZOLI, Carlo. O desenvolvimento de produtos sustentáveis: os requisitos ambientais de produtos industriais. 1. ed. 2. reimpr. CARVALHO, A. Traduzido por: São Paulo: Editora da Universidade de São Paulo, 2008. Título original: Lo sviluppo di prodotti sostenibili: I requesiti ambientali dei prodotti industriali.

MENICHINELLI, M. A framework for understanding the possible intersections of design with open, P2P, diffuse, distributed and decentralized systems. Disegno - The Journal of Design Culture, v. 3, n. 1-2, p. 44-71, 2016. 
MONTEMEZZO, M. C. DE F. S. Diretrizes metodológicas para o projeto de produtos de moda no âmbito acadêmico. 96 f. Dissertação (Mestrado em Design) - Faculdade de Arquitetura, Artes e Comunicação, Universidade Estadual Paulista, Bauru, 2003.

MOURA, Dácio Guimarães de; BARBOSA, Eduardo Fernandes. Trabalhando com projetos: planejamento e gestão de projetos educacionais. 8. ed. Petrópolis: Vozes, 2013.

MUL, J. DE. Redesigning design. In: ABEL, B. van Abel; Klaassen, R.; Evers, L.; Troxler, P. (Eds.). Open Design Now: Why Design Cannot Remain Exclusive. Amsterdam: BIS publishers, 2011. Disponível em: <http://opendesignnow.org/index.html?p=401.html . Acesso em: 19 nove. 2016.

NIINIMÄKI, K.; HASSI, L. Emerging design strategies in sustainable production and consumption of textiles and clothing. Journal of Cleaner Production, v. 19, n. 16, p. 1876-1883, 2011.

NEVES, H. Maker Innovation: do Open Design e Fab Labs ... às estratégias inspiradas no movimento Maker. $261 \mathrm{f}$. Tese (Doutorado em Arquitetura e Urbanismo) - Faculdade de Arquitetura e Urbanismo, Universidade de São Paulo, 2014.

PAZMINO, Ana Veronica. Design para ação social e sustentabilidade: incentivo em curso de design. CONGRESSO BRASILEIRO DE PESQUISA E DESENVOLVIMENTO EM DESIGN, 11, Gramado, 2014.

PIRES, D. A história dos cursos de design de moda no Brasil. Revista Nexos: Estudos em Comunicação e Educação, v. 6, n. 9, p. 1-13, 2002. Disponível em: $<\mathrm{http}: / /$ www.inovacaoedesign.com.br/artigos_cientificos/db_historia_escola_design_ moda_1_.pdf>. Acesso em: 19 mar. 2016.

. Design de moda: uma nova cultura. dObra[s], v. 1, n. 1, p. 66-73, 2007.

RICHARDSON, M. Pre-hacked: Open Design and the democratisation of product development. New Media and Society, v. 18, n. 4, p. 653-666, 2015.

SANCHES, Maria Celeste de Fátima. Projetando moda: diretrizes para a concepção de produtos. In: PIRES, Dorotéia Baduy (Org.). Design de moda: olhares diversos. São Paulo: Estação das Letras e Cores, 2008. p. 289-301.

STRIEN, M. Van; PONT, V. de. Open Source Fashion Manifesto. Rotterdam: Het Nieuwe Instituut, 2016.

THACKARA, J. Into the open. In: ABEL, B. van Abel; Klaassen, R.; Evers, L.; Troxler, P. (Eds.). Open Design Now: Why Design Cannot Remain Exclusive. Amsterdam: BIS publishers, $2011 . \quad$ Disponível em: <http://opendesignnow.org/index.html?p=403.html . Acesso em: 19 nov. 2016. 
THE POST-COUTURE COLLECTIVE. Post Couture Brazil. 24, fev. 2017. Disponível em: $\quad<$ http://www.postcouture.cc/news-backend/2017.2.26.24022017-post-couturebrasil>. Acesso em: 24 jun. 2017.

VEZZOLI, Carlo. Design de sistemas para a sustentabilidade: teoria, métodos e ferramentas para o design sustentável de "sistemas de satisfação". Tradução de: REGO, M. A. Salvador: EDUFBA, 2010.

Design e sistema de inovação para a sustentabilidade. In: DE CARLI, Ana Mery Sehbe; VENZON, Bernardete Lenita Susin (Org.). Moda, sustentabilidade e emergências. Caxias do Sul: Educs, 2012. p. 23-66.

Recebido em: 31/07/2017

Aceito em: 04/10/2017 